\title{
Unmet need for family planning in Indonesia and the policy strategy of intervention in several countries
}

\author{
Misnaniarti $^{1 *}$, Dumilah Ayuningtyas ${ }^{2}$
}

\begin{abstract}
${ }^{1}$ Master of Public Health, Department of Health Policy and Administration, Faculty of Public Health, Universitas Sriwijaya, Palembang, Indonesia

${ }^{2}$ Doctor of Health Policy and Politic, Department of Health Policy and Administration, Faculty of Public Health, Universitas Indonesia, Jakarta, Indonesia
\end{abstract}

Received: 27 March 2016

Accepted: 07 May 2016

\author{
*Correspondence: \\ Dr. Misnaniarti, \\ E-mail: misnaniarti@hotmail.com
}

Copyright: () the author(s), publisher and licensee Medip Academy. This is an open-access article distributed under the terms of the Creative Commons Attribution Non-Commercial License, which permits unrestricted non-commercial use, distribution, and reproduction in any medium, provided the original work is properly cited.

\begin{abstract}
The aims of this paper are to analyse the unmet need situation in Indonesia, identify determining factors and the intervention policy strategy in several countries. This paper was a literature study, taken from the data of the 2012 Indonesian Demographic and Health Survey (IDHS) and various other sources. It is seen that unmet need level in Indonesia decreases from time to time. During the 1991 to 2012 IDHS, total unmet need decreased from $17 \%$ to $11 \%$ (4.5\% for spacing and $6.9 \%$ for limiting). However, the number is considered still quiet high so an effort to solve it is needed. Determinants of unmet need can be associated with various factors such as demographical characteristic and social economic, education, culture, geographical access and condition in the area. Recommended to the government in order to develop policy strategy focused on intervention of unmet need determinants, improve financial resource allocation for access improvement of contraception service and develop capacity, improve service quality including staff training, and also public education in big scale to decrease social barriers.
\end{abstract}

Keywords: Unmet need, Contraception, Long term contraception, Family planning, Family planning policy, Indonesia

\section{INTRODUCTION}

Human resource development prospect in Indonesia in future is directed to the improvement of human resource quality, marked by increasing of Human Development Index (HDI), Gender Development Index (GDI), and reach of balanced population growth. Therefore, human resources quality is a valuable capital in country's development.

In order to decrease population's growth rate, government conducts Family Planning revitalization as one of national priority program. The big number of population does not give any benefit for development if it does not accompanied by the population's quality improvement. Thus, the sequence of population's development is directed to the effort of population's quantity control through contraception use, and the increase of population's quality by creating a quality small family.

People participation in Family Planning (FP) can be seen from their ability in accessing FP services independently or not. Family planning services are available at some government's health care providers for free through health insurance, like childbirth insurance (Jaminan Persalinan-Jampersal) in 2011 or National Health Insurance (Jaminan Kesehatan Nasional-JKN) available since 2014. In fact, sometimes there are a still person who receives FP service in private sector by paying for contraception. ${ }^{1}$ 
During the last decade, contraception prevalence has been stagnant and the increase of unmet need is occurred. As one of FP program indicator, number of FP participation (Contraceptive Prevalence Rate $=\mathrm{CPR}$ ), was expected to increase to $65 \%$ for modern method in 2015 . Modern method of CPR did not show a significant increase in the last ten years. The 2007 Indonesian Demographic and Health Survey (IDHS) showed CPR 57.4\% while from the 2012 IDHS it was known that modern method of CPR was $57.9 \%$. The target of family planning program which is still far from the goal deserves to be suspected in contributing the high amount of Infant Mortality Rate (IMR). Therefore, it is also necessary to investigated factors contributing in contraception use.,

Family Planning program in Indonesia, noted that increase of unmet need has been occurred from $8.4 \%$ in 2002/2003 to $9.1 \%$ in 2007 (using original definition). Even though, contraceptive use prevalence increased from $60.3 \%$ in $2002 / 2003$ to $61.4 \%$ in 2007 . While if it is seen about ideal number of children rate, it was decreased from 2.9 children in $2002 / 2003$ to 2.8 children in $2009 .^{4}$

Family planning participation is a birth control attempt which is expected to decrease population's growth rate and increase family welfare. Based on the 2012 IDHS, known that there are $62 \%$ married women using contraception. There are still a women who do not (yet) use contraception with some reasons while nowadays there are many options of contraception available, both simple and modern one. Injectables are the most widely used method of contraception $(32 \%)$, followed by pill $(14 \%)$. We need an appropriate policy strategy to increase FP participation of women in Indonesia.

According to National Population and Family Planning Board of Indonesia (Badan Kependudukan dan Keluarga Berencana Nasional-BKKBN), unmet need of contraception becomes the reason of $75 \%$ maternal mortality in Indonesia and in the world, and also affects population's growth rate so much. This tendency of high unmet need is need to be government's concern, because it will affect the FP program. The high amount of unmet need of contraception becomes the reason behind the high amount of Total Fertility Rate (TFR), and occurrence of unwanted pregnancy, finally if it continues to happen it will lead to population explosion in Indonesia. Therefore, purpose of this paper are to analyze the unmet need situation in Indonesia, identify determining factors and the intervention policy strategy in several countries. This paper conducted by narrative review, based on report of the 2012 IDHS, and also another sources.

\section{DISCUSSION}

Definition of unmet need base on the 2012 revision. Unmet need is an estimation of size and composition of women's population whom their contraceptive needs is not fulfilled. Women with unmet need for family planning include fecund women who do not use any kind of contraceptive but who wish to postpone the next birth (spacing) or stop childbearing altogether (limiting). The criteria used within the Demographic and Health Survey (DHS) to identify women with unmet need for family planning have been revised by Bradley et al. The change of unmet need definition for family planning aims to compare the level of unmet need by time and by country conducting DHS. ${ }^{5,6}$

\section{Situation analysis of Unmet need in Indonesia}

Total Fertility Rate (TFR) in Indonesia tended to decrease from 1991 to 2002 from 3.0 to 2.6, but after that became stagnant for one decade until 2012 (Figure 1).

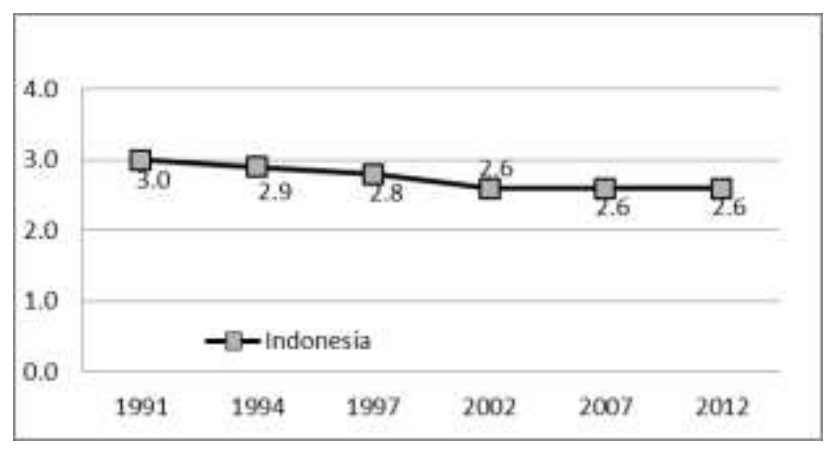

Sources: BPS, BKKBN, Measure IDHS, Publication from various years.

Figure 1: The trend of TFR in Indonesia from 1991 to 2012.

Table 1: The trend of Unmet need for family planning in Indonesia based on the 1991 to 2012 IDHS.

\begin{tabular}{|llll|}
\hline $\begin{array}{l}\text { Year of } \\
\text { survey }\end{array}$ & $\begin{array}{l}\text { Unmet need } \\
\text { for FP }\end{array}$ & $\begin{array}{l}\text { Met need for } \\
\text { FP (currently } \\
\text { using) }\end{array}$ & $\begin{array}{l}\text { Total } \\
\text { demand for } \\
\text { FP }\end{array}$ \\
\hline $\begin{array}{l}\text { The } 1991 \\
\text { IDHS }\end{array}$ & 17.0 & 49.7 & 66.7 \\
\hline $\begin{array}{l}\text { The } 1994 \\
\text { IDHS }\end{array}$ & 15.3 & 54.7 & 70.1 \\
\hline $\begin{array}{l}\text { The } 1997 \\
\text { IDHS }\end{array}$ & 13.6 & 57.4 & 71.0 \\
\hline $\begin{array}{l}\text { The } 2002- \\
\text { 2003 } \\
\text { IDHS }\end{array}$ & 13.2 & 60.3 & 73.6 \\
\hline $\begin{array}{l}\text { The } 2007 \\
\text { IDHS }\end{array}$ & 13.1 & 61.4 & 74.5 \\
\hline $\begin{array}{l}\text { The } 2012 \\
\text { IDHS }\end{array}$ & 11.4 & 61.9 & 73.2 \\
\hline
\end{tabular}

Source: 2012 IDHS Report

Data of unmet need for FP in Indonesia based on the 1991 to 2012 IDHS can be seen on Table 1. According to the 2012 IDHS report, estimation of unmet need on the previous IDHS could not be compared because of change in unmet need definition. Therefore, to provide a comparable estimate, the total unmet need and total demand for family planning has been recalculated using 
the new definition during period 1991 to 2007 IDHS. The result from recalculated available on Table 1 , it indicated that level of unmet need in Indonesia has been declining over time. Between the 2007 to 2012 SDKI, total unmet need in Indonesia decreased from $13 \%$ to $11 \%$. The impact of decline in unmet need, total demand of family planning service decreased slightly, while proportion of fulfilled total need of family planning increased slightly. ${ }^{5}$

Table 2: The amount of Unmet need for family planning in Indonesia from 1991 to 2012.

\begin{tabular}{|llll|}
\hline $\begin{array}{l}\text { Year of } \\
\text { Survey }\end{array}$ & $\begin{array}{l}\text { Unmet need } \\
\text { for spacing }\end{array}$ & $\begin{array}{l}\text { Unmet need } \\
\text { for limiting }\end{array}$ & $\begin{array}{l}\text { Total } \\
\text { amount }\end{array}$ \\
\hline $\begin{array}{l}\text { The } 1991 \\
\text { IDHS }\end{array}$ & 8.6 & 8.4 & 17,0 \\
\hline $\begin{array}{l}\text { The } 1994 \\
\text { IDHS }\end{array}$ & 6.6 & 8.7 & 15,3 \\
\hline $\begin{array}{l}\text { The } 1997 \\
\text { IDHS }\end{array}$ & 5.9 & 7.7 & 13,6 \\
\hline $\begin{array}{l}\text { The } 2002- \\
\text { 2003 IDHS }\end{array}$ & 4.7 & 8.5 & 13,2 \\
\hline $\begin{array}{l}\text { The } 2007 \\
\text { IDHS }\end{array}$ & 4.8 & 8.3 & 13,1 \\
\hline $\begin{array}{l}\text { The } 2012 \\
\text { IDHS }\end{array}$ & 4.5 & 6.9 & 11,4 \\
\hline
\end{tabular}

Sources: Bradley, 2012 and IDHS, 2012.

Based on Table 1, it seen that total demand for FP services in Indonesia tended to increase from 1991 to 2012 , from $66.7 \%$ to $73.2 \%$. The increase of this demand was followed by the decrease of the unmet need FP, from $17.0 \%$ in 1991 to $11.4 \%$ in 2012. According to Bradley and the 2012 IDHS report, total unmet need for FP on married women aged 15-49 years in Indonesia in 2012 was $11.4 \%$, consisted of $4.5 \%$ for spacing and $6.9 \%$ for limiting (Table 2)..$^{5,6}$

Based on revised definition, it is known that nationally the amount of unmet need tended to decreased every year of survey. Nevertheles, the amount was still considered high so that an effort to solve it, is needed. Program plan composed to intervention the hight amount of unmet need can be started by identifying factors associating with unmet need.

\section{Factors associated with Unmet need}

There are many factors associated with unmet need FP. Generally, the main cause women with unmet need do not use modern contraception are the lack of pregnancy risk understanding, potential side effect and worries about health, less exposed with pregnancy risk, contraceptive prohibition because there are disapproval from husband or religious reasons and also because it cost, do not want to busy, also subjective experience that pregnancy did not even occur without contraception. ${ }^{7}$
Empirical evidence in West Nusa Tenggara showed that unmet need associated with factors age, parity, women's education, husband's education, economic status (wealth index), and health/FP fieldworkers visited. ${ }^{8}$ So did the research at Klabang District, Bondowoso Regency that married women with elementary school educational and without any educational respectively had a risk 1.6 times bigger (95\% CI: 0.34-1.35) and 1.2 times bigger $(95 \%$ CI: 0.30-5.38) to experience unmet need for FP than women with junior to senior high school and higher education level. Women in pre-prosperous (pra-sejahtera) family group had a risk 1.6 times bigger (95\% CI: 0.28 1.37) to experience unmet need FP than prosperous level II family group or higher. ${ }^{9}$

Similar with use of contraception, it is known to associate with the health insurance membership (variable contribution is $7.0 \%$ ), controlled by variable age, education, job, parity, perception about ideal number of children, husband's education, husband's job, and role of media. ${ }^{10}$ From the result of other study, it was known that factors associating with FP participation are economic status $(\mathrm{OR}=1.429 ; \mathrm{p}=0.000)$, women's education $(\mathrm{OR}=0.737 ; \mathrm{p}=0.000)$, parity $(\mathrm{OR}=1.608 ; \mathrm{p}=0.000)$, source of FP information through discussion $(\mathrm{OR}=1.834$; $\mathrm{p}=0.000$ ), source of information through FP services and public figure. ${ }^{11}$

Based on study in Burkina Faso, the rather high amount of unmet need occurred to women whose husband's education was at least in secondary level (54.4\%). It was seemed significantly lower in the household for the use with husbands' approval than without. ${ }^{12}$ In Cairo, one of risk factors of unmet need was husbands disapproval in using contraception with $\mathrm{OR}=2.96 ; 95 \% \mathrm{CI}=1.47-5.97 .^{13}$ In six cities in Iran was also mentioned that family disapproval also became the reason of the high unmet need. ${ }^{14}$ Factors of parity and use of modern contraception was also proved to associate with the occurrence of unwanted pregnancy in Khartoum, Sudan. ${ }^{15}$

From the 2012 data, amount of unmet need increased in accordance with age, the highest was $16 \%$ for married women aged 45-49 years. Almost all of unmet need on women under 25 years old was intended for spacing. Unmet need for limiting sharply increased on women aged 35 or more and the highest was $15 \%$ for women aged 45-49 years. The amount of unmet need increased in accordance with the number of children and reach $21 \%$ for women with five or more children. Most of unmet need on women with three or more children was intended for limiting. The amount of unmet need in rural (12\%) was rather higher than urban $(11 \%)$. Percentage of unmet need was not too vary based on educational category. ${ }^{5}$

Unmet need of FP phenomena indicates the gap between purpose of women's reproduction and their contraception use behavior. It means that women have willingnes to avoid pregnancy but do not perform any pregnancy prevention act. This determinants of this unmet need of 
FP can be associated with various factors such as demographical and socio economic, characteristic, education, culture, geographical situation and access in an area. Other factors which were also identified as determinants of unmet need of FP were area and region which also have a role in the use of contraception, where the use proportion was higher if it was available in facility, or in area with more favorable-provider service. ${ }^{16}$

\section{Policy strategy}

An estimate of the size unmet need is very important to be concerned for planning purpose in reproductive health programs, and because the decrease of unmet need percentage will give a significant result to CPR. The study found that by provided service to unmet need group can help the family to control pregnancy and increase their social economy. Other study showed by decreasing unmet need, maternal and infant mortality can be decreased. ${ }^{4}$

The benefit of finding out the size and characteristic of unmet need can help planning and strengthening the FP program. Data of contraception use and needs trend is necessary for program guideline, policy decision, and monitor achievement of Goals 5 MDGs which was called as universal access in contraception services. ${ }^{17}$ Through information of several research results, it is expected that umnet need data can be available, so that cultural, contextual obstacles and service weakness can be identified for program and policy improvement in the future. $^{18}$

The benefit of contraception use based on longitudinal research in India, proved that women using contraception has smaller probabilty of pregnancy or givebirth. ${ }^{19}$ Based on estimation in 2008 of developing countries, the meet of FP needs in order to decrease unwanted pregnancy can save cost around $\$ 5.1 .^{20}$

Information about unmet need FP is important to develop efforts of family planning program in the future. Therefore, the main goal of FP program is the group of unmet need, and postpartum. ${ }^{2}$ The unmet need of FP treatment needs a consistent and sustainable attempts and also supported by government's policy in central and local. Result of studies in several countries, identification of unmet need of FP can globally decreased maternal mortality as much as $29 \% .^{21}$ Furthermore, from other study it is known that if all women in developing countries who wants to prevent pregnancy use an effective method of contraception, maternal mortality can be decreased to $30 \%$ by complience of unmet need of contraception. $^{22}$

Based on the study in countries with high birth rate, the implementation of FP potential to avert $32 \%$ of maternal mortality by preventing unintended pregnancy and can decrease nearly $10 \%$ of childhood deaths, by decreasing the less than two years birth spacing. The several keys to effective and sustainable FP program are well established: high-level political commitment, a broad coalition of support from elite groups, adequate funding, legitimation of the idea of smaller families and modern contraceptive through mass media and others, and making a range of methods available through medical facilities, social marketing, and outreach of services. ${ }^{23}$

Besides, The repositioning of family planning services in many countries is made more difficult by the diverse efforts at health sector reform and decentralization of health decision making. ${ }^{24}$ For example in Indonesia, some regulation made by government to increase the access of free charge deliver process like Jampersal policy, eventhough the purpose is to decrease maternal mortality, but psychologically it can decrease the worries of givebirth cost absence so that women feel more ready and financially capable (affordable) to pregnant and give birth again. $^{8}$

In facing this situation, government needs to make a policy strategy and program to decrease unmet need for FP. The strategy implemented in some countries, like in Burkina Faso such as emphasis on husbands' approval and health education about benefits of FP services. The purpose is to prevent and reduce the unmet need of modern contraception. ${ }^{12}$

Intervention to reduce unmet need is relevant to increase the use of contraception in India and four countries in East Africa, by supplying high quality resources and infrastructure to support FP services such as the availability of private room which assure visual and auditory privacy in counseling, the increase of contraception access in rural, the increase of health officers motivation related to FP program, free contraception supply, and many other. Besides, generally the FP program provider is supervised routinely. ${ }^{16,18}$

Other strategies to met of unmet need modern contraception in developing countries are: first, we need to increased allocation of financial resources to improve access to contraceptive services and expand capacity. Second, improve the high-quality services, including staff training to increase the accurate information, respectfull care, and adequate counseling. Third, large-scale public education intervention are needed to reduce social barriers in contraception use. ${ }^{17}$

The programs considered potential to increase the access of limiting birth, although the impact can not be seen yet. The important things are what strategy to do, and then what the implication is to the policy and program in order to intervention unmet need. ${ }^{18}$ Developing countries are suggested to conduct continuous program to assure the importance of health system and give support to FP services, to increase contraception use. ${ }^{24}$ Therefore, in Indonesia, an effective method is needed to increase public awareness in FP and highly supported by fund, the 
increase of FP facilities which can afford underdeveloped areas, inlands and islands. ${ }^{25}$

\section{CONCLUSION}

Based on recalculation using the revised definition of unmet need, it is known that the unmet need in Indonesia tends to decrease from time to time. In the 1991 to 2012 IDHS, total unmet need decreased from $17 \%$ to $11 \%$ (4.5\% for spacing and $6.9 \%$ for limiting). But this amount is still considered quiet high so an efforts to intervention it, is needed. The determinants of unmet need can be associated with various factors such as demographical and social economic characteristics, education, culture, access and geographical condition of an area. Based on several studies it is known that associated factors are age, parity, women's education, residence, husbands' education, economic status, husband and family support, and the visit of health/FP fieldworkers.

Through the information from several research result related to unmet need, data is expected to available so that cultural, contextual barriers and service weakness can be identified for FP program and policy improvement in the future. Recommended for Government to develop a policy strategy of unmet need intervention which focused on determinant factors. Other strategies are the needs to increase financial resource allocation to improve access to contraception services and develop capacity, improve the service quality including staff training, and finally expand the large-scale of education intervention to reduce social barriers.

\section{ACKNOWLEDGEMENTS}

The authors would like to thank for Anwar Fachry from Research Center for Population and Development, Universitas Mataram for his assistance in this paper material previously.

Funding: No funding sources Conflict of interest: None declared

Ethical approval: Not required

\section{REFERENCES}

1. BKKBN. Analysis and evaluation of Independent Family Planning services 2013 [Indonesian]. Jakarta: Reporting and Statistics Directorate of the National Population and Family Planning Board of Indonesia; 2014.

2. Mujiati I. Postpartum family planning services in Supporting Efforts to Accelerate Decrease Maternal Mortality Rate [Indonesian]. Buletin Jendela Data dan Informasi Kesehatan, Indonesia's Ministry of Health. 2013;2(2):11-6.

3. BKKBN. Analysis and Evaluation of the Implementation of Family Planning Program; Materials for preparation of the National Working Meeting [Indonesian]. Jakarta: Reporting and
Statistics Directorate of the National Population and Family Planning Board of Indonesia; 2014.

4. Juliaan F. Unmet Need and need Family Planning services in Indonesia (Further analysis 2007 IDHS) [Indonesian]. Jakarta: Penerbit KB dan Kesehatan Reproduksi, National Population and Family Planning Board of Indonesia; 2009.

5. Statistics Indonesia, National Population and Family Planning Board, Ministry of Health, and ICF International. Indonesia Demographic and Health Survey 2012. Jakarta, Indonesia: BPS, BKKBN, Ministry of Health, and ICF International; 2013.

6. Bradley S, Croft TN, Fishel JD, Westoff CF. Revising Unmet Need for Family Planning: DHS Analytical Studies No. 25 Calverton, Maryland, USA: ICF International and The Office of Population Research, Princeton University; 2012.

7. Westoff CF. Unmet Need for Modern Contraceptive Methods. DHS Analytical Studies No. 28. Calverton, Maryland, USA: ICF International; 2012.

8. Ayuningtyas D, Oktaviana W, Misnaniarti. Factors contributing to unmet need for contraception in Nusa Tenggara Barat, Indonesia. Journal of Reproduction and Contraception. 2015;26(4):239-48.

9. Katulistiwa R, Baroya Nm, Wati DM. Determine of unmet need for Family Planning on married women at Klabang District, Bondowoso Regency [Indonesian]. Jember: Department of Epidemiology and Population Biostatistics, Faculty of Public Health, Universitas Jember; 2014.

10. Misnaniarti. Women's participation in Health Insurance and contraception use in Indonesia [Indonesian]. Indralaya: Faculty of Public Health, Universitas Sriwijaya cooperation with National Population and Family Planning Board of Indonesia; 2015.

11. Ivanty R. Factors Associated with Family Planning Participation on women of childbearing age in Indonesia; Analysis of 2012 IDHS data [Indonesian]. Depok: Faculty of Public Health, Universitas Indonesia; 2014.

12. Adebowale SA, Palamuleni ME. Determinants of unmet need for modern contraception and reasons for non-use among married women in rural areas of Burkina Faso. African Population Studies. 2014;28(1):499-514.

13. Kotb MM, Bakr I, Ismail NA, Arafa N, El-Gewaily M. Women in Cairo, Egypt and their risk factors for unmet contraceptive need: a community-based study. Journal of Family Planning and Reproductive Health Care. 2011;37(1):26-31.

14. Motlaq ME, Eslami M, Yazdanpanah M, Nakhaee N. Contraceptive use and unmet need for family planning in Iran. International Journal of Gynecology and Obstetrics. 2013;121(2):157-61.

15. Sabahelzain MM, Abdalla SM, Meraj SA, Mohamed E, Almansour MA, Medani KT, et al. Prevalence and factors associated with unintended pregnancy among married women in an urban and rural community, 
Khartoum state, Sudan. Global Journal of Medicine and Public Health. 2014;3(4).

16. Wang W, Wang S, Pullum T, Ametapi P. How Family Planning Supply and the Service Environment Affect Contraceptive Use: Findings from Four East African Countries. DHS Analytical Studies No. 26. Calverton, Maryland, USA: ICF International; 2012.

17. Darroch JE, Singh S. Trends in contraceptive need and use in developing countries in 2003, 2008, and 2012: an analysis of national surveys. The Lancet. 2013;381(9879):1756-62.

18. Khan M, Hazra A, editors. Unmet need for contraception in India: Review and recommendations. Report on the workshop on Operationalising the Call for Elimination on Unmet Need for Family Planning; 2012.

19. Speizer IS, Calhoun LM, Hoke T, Sengupta R. Measurement of unmet need for family planning: longitudinal analysis of the impact of fertility desires on subsequent childbearing behaviors among urban women from Uttar Pradesh, India. Contraception. 2013;88(4):553-60.

20. Singh S, Darroch JE, Ashford LS, Vlassoff M. Adding It Up: The costs and Benefits of Investing in family Planning and maternal and new born health. New York: Guttmacher Institute, and United Nations Population Fund (UNFPA); 2009.

21. Ahmed S, Li Q, Liu L, Tsui AO. Maternal Deaths Averted by Contraceptive Use: an Analysis of 172 Countries. The Lancet. 2012;380(9837):111-25.

22. Cleland J, Conde-Agudelo A, Peterson H, Ross J, Tsui A. Contraception and Health. The Lancet. 2012;380(9837):149-56.

23. Cleland J, Bernstein S, Ezeh A, Faundes A, Glasier A, Innis J. Family planning: the unfinished agenda. The Lancet. 2006;368 (9549):1810-27.

24. Townsend JW, Jacobstein R. The changing position of IUDs in reproductive health services in developing countries: opportunities and challenges. Contraception. 2007;75(6):S35-40.

25. BAPPENAS (National Development Planning Board of Indonesia). Evaluation Family Planning services for poor family (Pre-Prosperous Family and Prosperous Family-1) [Indonesian]. Jakarta: Directorate of Population, women enpowerment, and child protection, Deputy Human Resources and Culture, The National Development Planning Board of Indonesia; 2010.

Cite this article as: Misnaniarti, Ayuningtyas D. Unmet need for family planning in Indonesia and the policy strategy of intervention in several countries. Int J Reprod Contracept Obstet Gynecol 2016;5:1680-5. 